\title{
ASPECTOS CONSTRUCTIVOS PUESTOS DE MANIFIESTO EN LA RESTAURACIÓN DEL PARK GÜELL DE BARCELONA
}

\section{(CONSTRUCTIVE ASPECTS UNVEILED IN THE RESTORATION OF THE PARK GÜELL IN BARCELONA)}

Josep Rovira i Pey, Arquitecto.

Servicio de Patrimonio Arquitectónico de la Diputación de Barcelona. España

$109 \cdot 13$

Fecha de recepción: $17-\mathrm{V} 11-90$

\section{RESUMEN}

En el Park Güell de Barcelona, uno de los paisajes más bellos creados por la arquitectura, las formas naturales y las creadas por la imaginación del autor se entremezclan en una armonia sugestiva, inquietante. Para construir esas formas,

Gaudi echó mano de su intuición estructural y se arriesgó a utilizar algunos materiales de una forma singular. Sólo la disección a la que ha obligado la restauración de la obra envejecida, nos ha permitido conocer algunos de sus entresijos. La sorpresa, o los reparos que nos producen algunas soluciones, no hacen variar, no obstante, la consideración respecto a la portentosa capacidad intuitiva y creativa de Gaudi.

\section{SUMMARY}

The Park Güell of Barcelona, by Antoni Gaudi, is one of the most beautiful architectural landscapes ever conceived by man. The natural forms and those created by the author intermix in a suggestive and disturbing harmony. To construct these forms, Gaudi resorted to his structural intuition and risked using certain materials in an original manner. Only the dissection forced by the restoration of this aging work has allowed us to unravel some of its enigmas. The surprise produced by some of the solutions, does not alter, nonetheless, our considerations towards the powerful intuitive and creative capacity of Antoni Gaudi.
Con la finalidad de promover una "ciudad jardín" inspirada en los modelos urbanísticos ingleses basados en las teorias de William Morris y Ebenezer Howard, el conde Güell compró en 1899 una finca situada en la llamada Muntanya Pelada, una de las colinas que rodean el llano de Barcelona.

El proyecto de esta promoción urbanística privada, que desde un principio fue denominada Park Güell (1), fue encargado a Antoni Gaudí, quien en un estudio inicial del terreno se percató de las dificultades que presentaba, dado que era un lugar pedregoso, de mucha pendiente y falto de agua. Gaudí proyectó las calles de la urbanización adaptándolas a la topografia del terreno, procurando evitar los desmontes y terraplenes, ondulando el trazado, previendo viaductos y uniformando la pendiente de los perfiles. La zona central de la urbanización, cuyo recinto se cerraba con un muro perimetral, era ocupada por una gran plaza porticada, llamada Templo Dórico o Sala Hipóstila, destinada a mercado. Desde la entrada, flanqueada por dos bellos pabellones destinados a portería y servicios, se accedía a la plaza por una gran escalinata desdoblada presidida por la figura del dragón y el escudo de Catalunya. Sobre el mercado se extendia una gran plaza abierta contorneada por un serpenteante y sorprendente banco de perfil anatómico. 


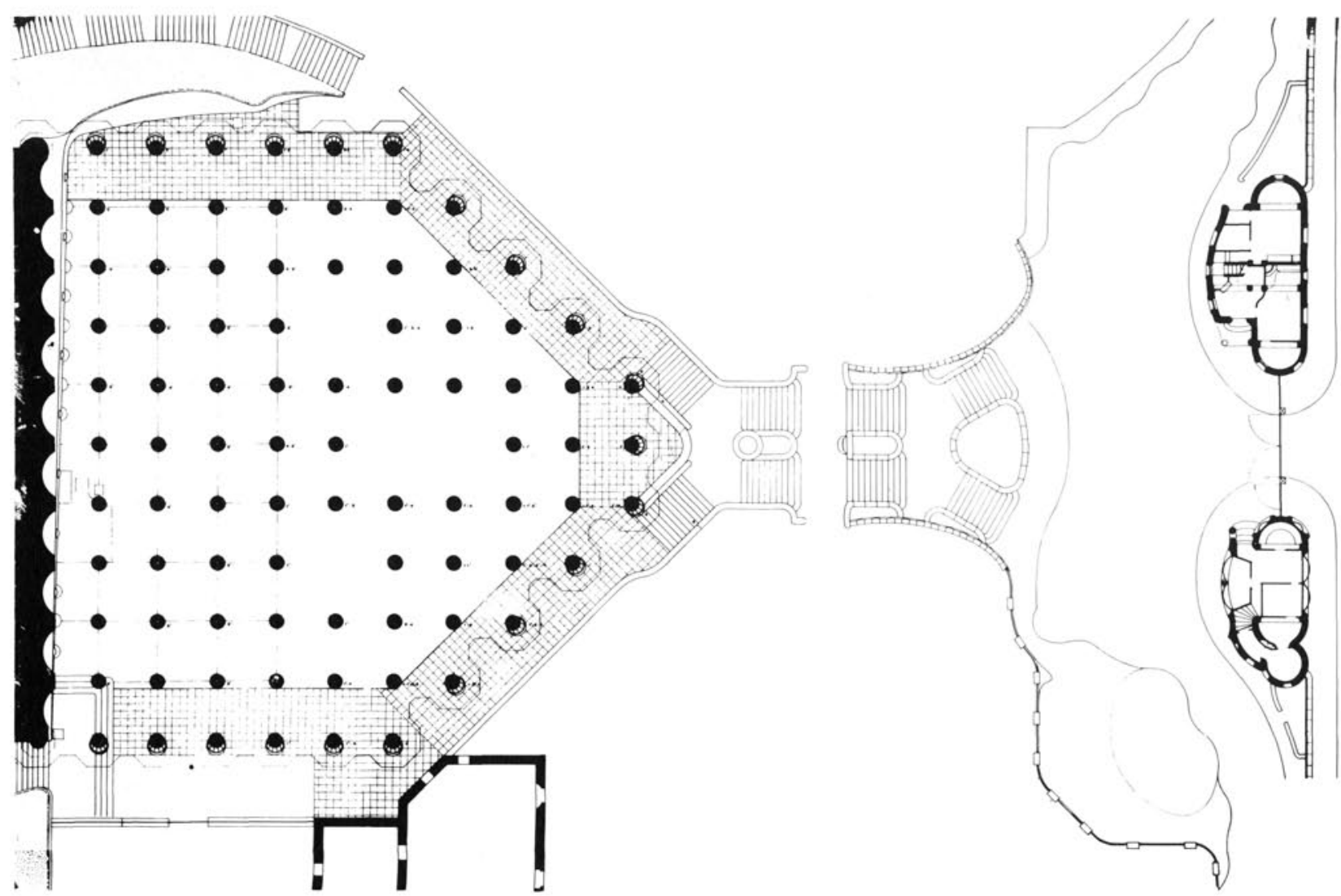

Fig. 1.-Planta de la Sala Hipóstila, acceso, pabellones que flanquean la puerta principal y la escalinata.

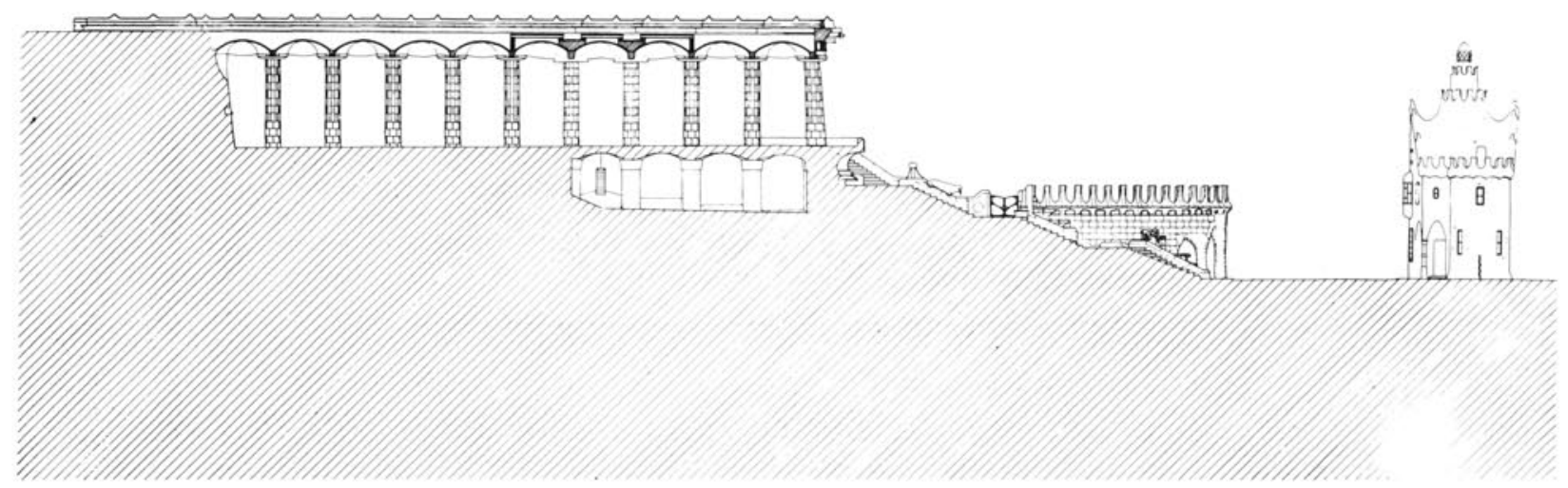

Fig. 2.-Sección longitudinal de la planta anterior.

La ciudad-jardin estaba concebida para albergar 60 parcelas de 1.100 a $2.000 \mathrm{~m}^{2}$. Sólo fueron delimitadas 12 de ellas, y de éstas sólo dos fueron edificadas, incluido el chalet-muestra - proyectado por Francesc Berenguer y construido por José Pardo, contratista del parque-, que más tarde utilizó Gaudi como vivienda hasta poco antes de su muerte. La promoción fue un fracaso económico y en 1922 los terrenos fueron ven. didos al Municipio, que los destinó a parque público, conservándose su denominación original.
En la pasada década el Ayuntamiento de Barcelona so. licitó del Ministerio de Cultura la restauración del conjunto, cuyo estado de conservación empezaba a ser muy deficiente. Por encargo del ministerio los arquitectos J.A. Martínez Lapeña y Elias Torres Tur elaboraron en 1985 un informe que detectaba los problemas fundamentales y en el que se hacian, entre otras, las propuestas de actuación siguientes: T.-Repoblación forestal, mejora de la jardineria y habilitación de una gran superficie libre para el desarrollo de actividades 
que se realizan actualmente en zonas que contienen elementos de más difícil conservación (Sala Hipóstila, banco perimetral y revestimientos cerámicos en general). 2.-Construcción de un nuevo acceso, aparcamientos, vallado de todo el recinto y mejora del acceso para el control del parque. 3.-Limpieza, reparación y adecuación de los pabellones de entrada para ubicar una exposición sobre la historia del parque, y adecuación de una edificación para concentrar los servicios. 4.-Consolidación y restauración de los viaductos, muros, bancos de mampostería, etc., y como más urgente, la reparación de la Sala Hipóstila, que conlleva la impermeabilización, la nueva pavimentación y la mejora del desagüe de la plaza superior, para solucionar definitivamente la problemática que subsiste a pesar de las restauraciones efectuadas anteriormente. La reparación del banco, tanto en lo que respecta a su estructura como a su revestimiento, así como la reconsideración de algunas intervenciones anteriores (restauración de los azulejos del "trencadís", etc.) debian plantearse igualmente según este informe.

Tal como se sugirió, el primer proyecto redactado contempló, en dos fases, la restauración de la Sala Hipóstila y el banco perimetral, que eran los elementos que presentaban un mayor grado de deterioro.

Las obras realizadas hasta el inicio del verano de 1990 , han consistido en la restauración, ya concluida, de los cimientos, pilares y techos de la sala de las columnas y la del entablamento de coronación que actúa como respaldo del banco perimetral, obra que continúa en la actualidad.

La restauración del techo de la Sala Hipóstila tuvo en cuenta un informe redactado por la Oficina Consultora Técnica del Colegio de Arquitectos de Cataluña, cuyo director, el arquitecto Fructuós Mañá, ha asesorado los temas estructurales, constructivos y patológicos de la obra.

En este informe se citaban como patologias más importantes las humedades en techo y columnas por un mal funcionamiento del sistema de desagüe de la cubierta, asi como las fisuras por esfuerzos de tipo estructural en cúpulas y dinteles.

El proyecto abordó la solución de estas patologías en base a la restauración de los elementos estructurales en mal estado, la impermeabilización de la cubierta, la construcción de un sistema eficaz de desagüe, y por último, la restauración de los revestimientos de azulejos de dinteles y cúpulas.

Previamente a la realización de estos trabajos restauratorios, hubo que realizar las habituales prospeccio- nes. En el caso de la obra de Gaudí, estos estudios previos se convierten en realidad en trabajos de investigación constructiva ya que por el talante de su actuación -improvisaba las soluciones de detalle- y la pérdida de toda documentación grática, sólo es posible conocer su modo de construir cuando la obra se disecciona antes de ser restaurada.

La estructura de la sala que soporta la gran plaza, se apoya sobre las ochenta y seis columnas construidas de las noventa previsibles según el trazado. Los pilares consisten en un molde de ladrillo, que sirve de encofrado, rellenos de un hormigón de mortero de cal con piedras. En el momento de construirlos colocaban un rollizo de madera en el eje, que se retiraba después de fraguado para dejar el conducto de desagüe que conducia a la cisterna. Por su parte exterior los pilares se revocaban simulando piedra en la parte alta y se recubrian con cerámica en la parte baja.

Cada pilar se corona con un capitel dórico, que es una pieza prefabricada de argamasa de mortero de cal. Encima de los capiteles se apoyan los dinteles, formados con piezas de cerámica unidas por unos flejes a base de pasamanos retorcidos de hierro forjado, que hacian más adherente la unión entre el mortero de cal y el ladrillo. Sobre cada capitel, se apoyan cuatro dinteles entre los cuales se deja el hueco de comunicación del desagüe de la plaza con el bajante en los pilares situados encima de la cisterna. Los dinteles son también prefabricados y están formados por ladrillos y haces de flejes. Tienen la sección mayor del ladrillo en la zona central, que es donde el momento flector es mayor. Sobre los dinteles se apoyan las cúpulas, que también eran prefabricadas y autoportantes, construidas con doblado de ladrillo y con un fleje que absorbía las tracciones que se producian en su base.

Cuando se ha acometido la restauración se ha comprobado que todos los dinteles se habian roto por falta de resistencia a la flexión y por la corrosión a que está sometida toda la pieza debido a las filtraciones de agua y al ambiente salino de Barcelona.

El conjunto de la Sala Hipóstila estaba muy bien resuelto desde el punto de vista constructivo, teniendo muy claro el principio estructural y donde existian las tracciones; en cambio no estaban bien resueltos los problemas de durabilidad de los materiales. El pH del mortero de cal era muy bajo, lo cual hacía que se oxidaran los flejes, y por eso se deterioraban los dinteles que amenazaban la ruina del conjunto, a causa de las filtraciones del agua de lluvia que corría por el intradós de las cúpulas, y cualquier fisura dejaba pasar el agua que impregnaba la masa de la cerámitca, muy cargada en sales. 


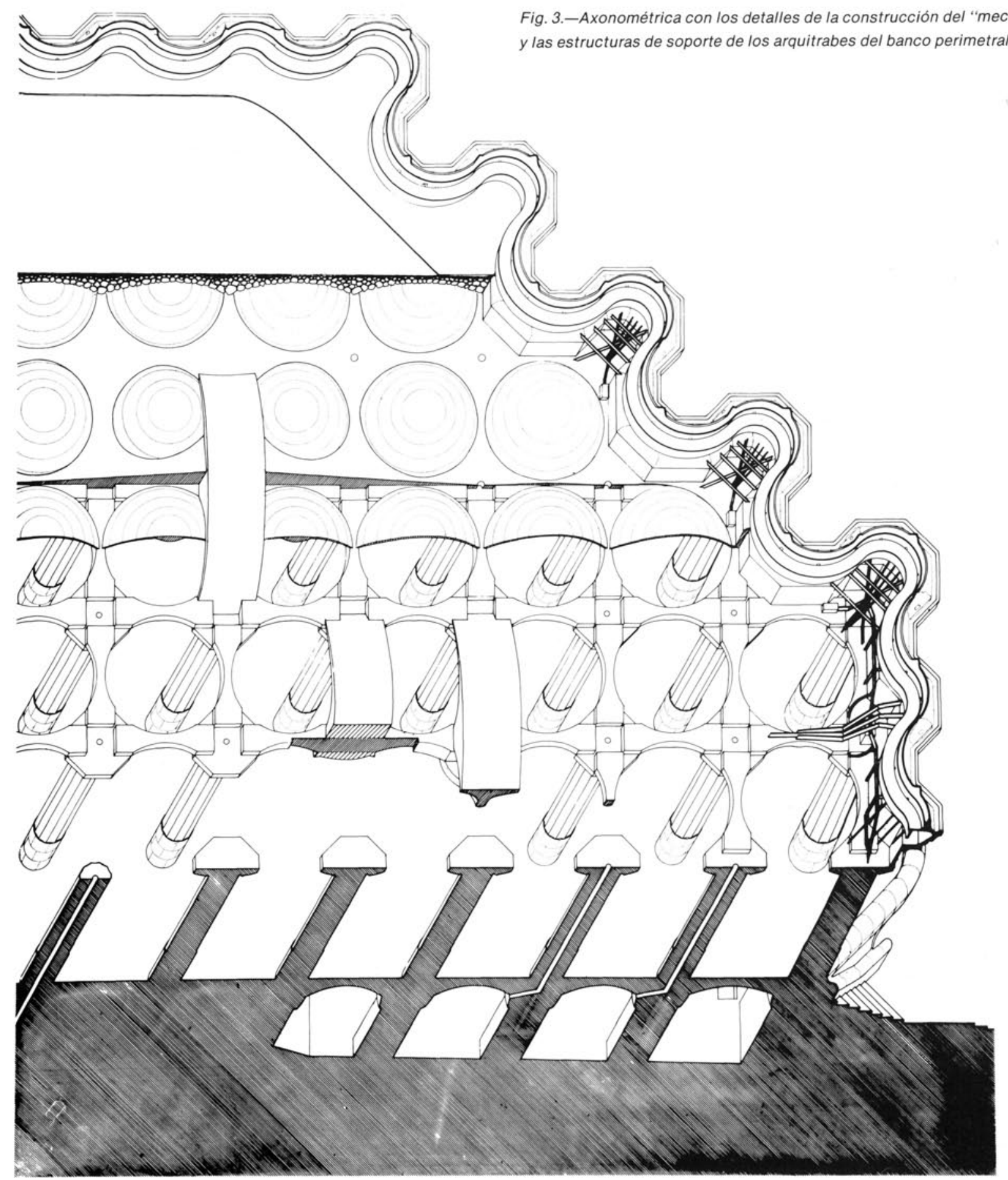

Existia también un problema de asentamientos localizado en el frente de la Sala Hipóstila. Una parte de la columnata se asentaba sobre roca firme y la otra, la zona de la cisterna, sobre un terreno cuaternario de sobreposición.

Al ser la Sala Hipóstila una estructura en porche y estar expuesta por todas sus partes, superior e inferior, a las condiciones ambientales, se produjeron movimientos térmicos que produjeron también fisuras ini- ciales, las cuales provocaron aquellas filtraciones de agua. El retranqueo de la cisterna hace que ésta funcione como un contrafuerte a tracción, cuyos esfuerzos horizontales produjeron fisuras y una pérdida de agua y el empapamiento del suelo. Para solucionar esto se recalzaron los pilares perimetrales y algunos interiores, desde arriba, inyectando dichas columnas.

En la planta de la Sala Hipóstila, lostramos que salvaban el espacio de tres pilares, por falta de uno de ellos, 


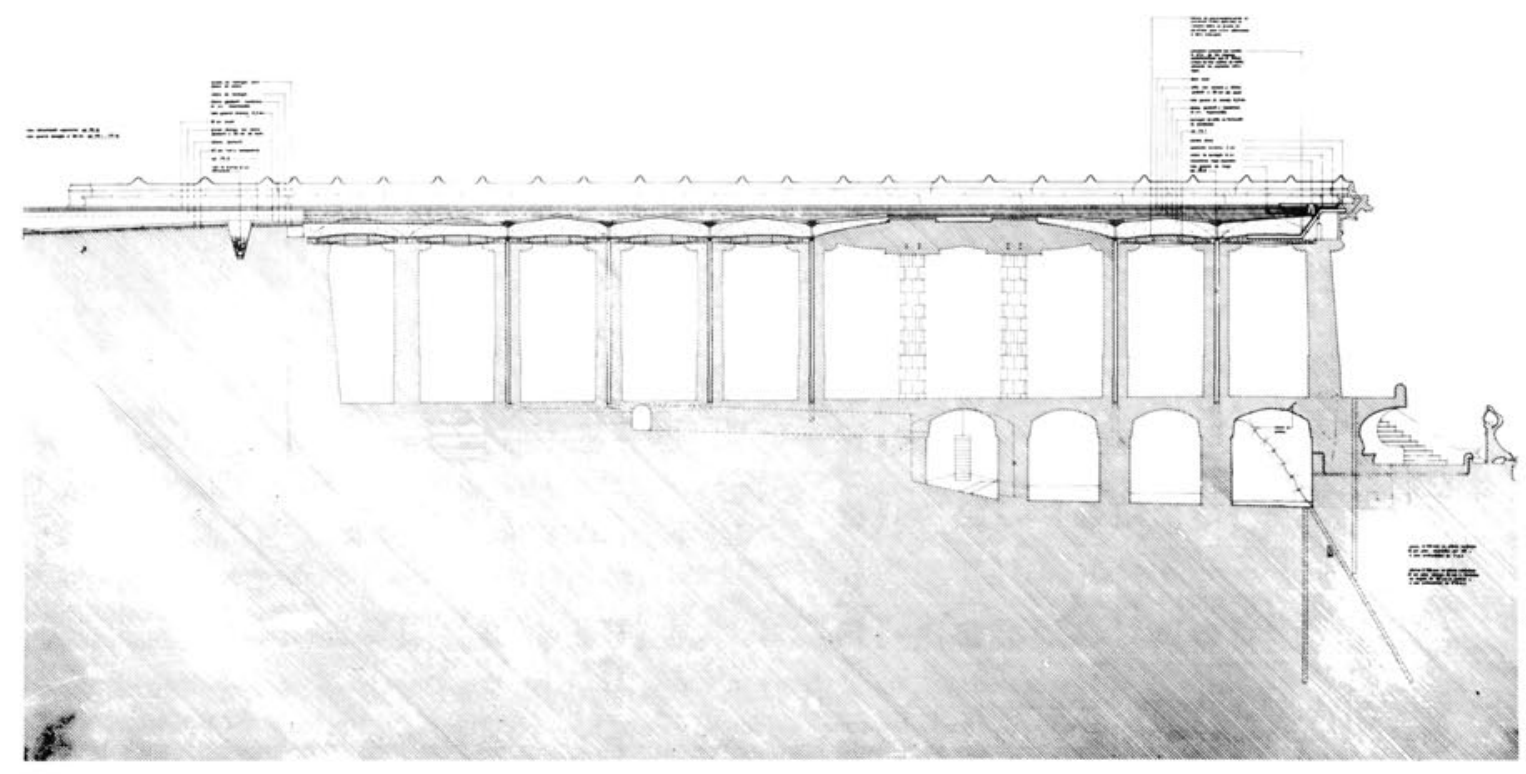

Fig. 4.- Sección de la Sala Hipóstila y la cisterna. (Proyecto de restauración).

estaban cubiertos con un gran arco muy rebajado formado por roscas de maón y un gran tirante formado por un haz de flejes paralelos y entrelazados en el centro; dicho arco sostenía un elemento colgante de ladrillo decorado por su parte inferior por unos grandes medallones de 'trencadis' de cerámica y vidrio. En una reparación efectuada en los años cincuenta se temió por los grandes empujes que podian dar los arranques de unos arcos tan rebajados como aquéllos y por ello se cubrió con unos forjados soportados sobre paredes apoyadas en los casquetes. Al hacer una prospección en estos puntos se pudo ver el estado y dimensión de los flejes que hacian de tirante de tracción del arco y se comprobó que formaban un sistema perfectamente estable en el cual se habia cuidado mucho la ejecución, por lo cual no habia sufrido entradas de agua y los flejes estaban en perfecto estado. En la actual restauración se ha restituido el equilibrio inicial del sistema y no hizo falta ninguna reparación en estos puntos de la estructura.

Otra sorpresa, fruto de la prospección previa a la restauración, ha sido la estructura ingeniada por Gaudi para sustentar el entablamento perimetral de la plaza -que, como se ha dicho, es a su vez el remate posterior del banco-. Este entablamento, con su arquitrabe, friso y cornisa, tiene un vuelo y un volumen considerable. Sustentada sobre una estructura porticada formada por perfiles laminados de hierro en "I" y roblonados para sus uniones, esta estructura gana el voladizo necesario para su construcción. Su estructura principal se encontró en bastante buen estado, no asi la estructura que estaba incorporada a la cáscara de fábrica de obra de su perimetro, formada a base de los flejes retorcidos. El buen estado de la armadura principal se supone que ha sido porque los flejes, que son de acero forjado -el cual es mucho más reactivo, es decir, más oxidable, que el acero laminado- han actuado como armadura de sacrificio y han dejado intacta y en buen estado la estructura del pórtico principal.

Esta estructura porticada se sustenta sobre unos pilares de obra, solución no muy ortodoxa, y sobre aquéIla se apoyan los tres perfiles que soportan el voladizo por un lado y por el otro se empotra sobre los dinteles de la sala, anclados a ellos sobre un macizo. La estructura porticada está inclinada respecto a la vertical para absorber los empujes de todo el conjunto estructural.

Sobre los perfiles, en voladizo, corre otro perfil en "I" alabeado que sigue la orla del banco y que hace que la cáscara que se apoya en él, eche las aguas fuera del banco.

Para sustentar los voladizos de mayor diámetro, más salientes, se ha utilizado una técnica diferente y no tan ingeniosa y bella como la anterior. Está tratada como la estructura de una copa con un tirante traccionado en la parte superior y una serie de aletas que actúan como varillas a compresión. Al no ser una copa cerrada surgian problemas que se solucionaron colocando unos tirantes horizontales a nivel en la parte superior y para evitar el vuelco se situaron otros tirantes anclados a los dinteles con una gran masa de mortero, lo cual resulta una enorme chapuza constructiva aunque sea realmente eficaz.

El banco estaba formado por dos piezas prefabricadas de ladrillo revestidas de 'trencadis', una que sirve de asiento y otra de respaldo, y seguian la modulación de semicírculos o cuartos de círculo de la ondulación del banco. El banco se apoya sobre la estructura descrita anteriormente y con la cual se consiguiơ un plano totalmente horizontal sobre el que se montó el banco de obra cerámica. 


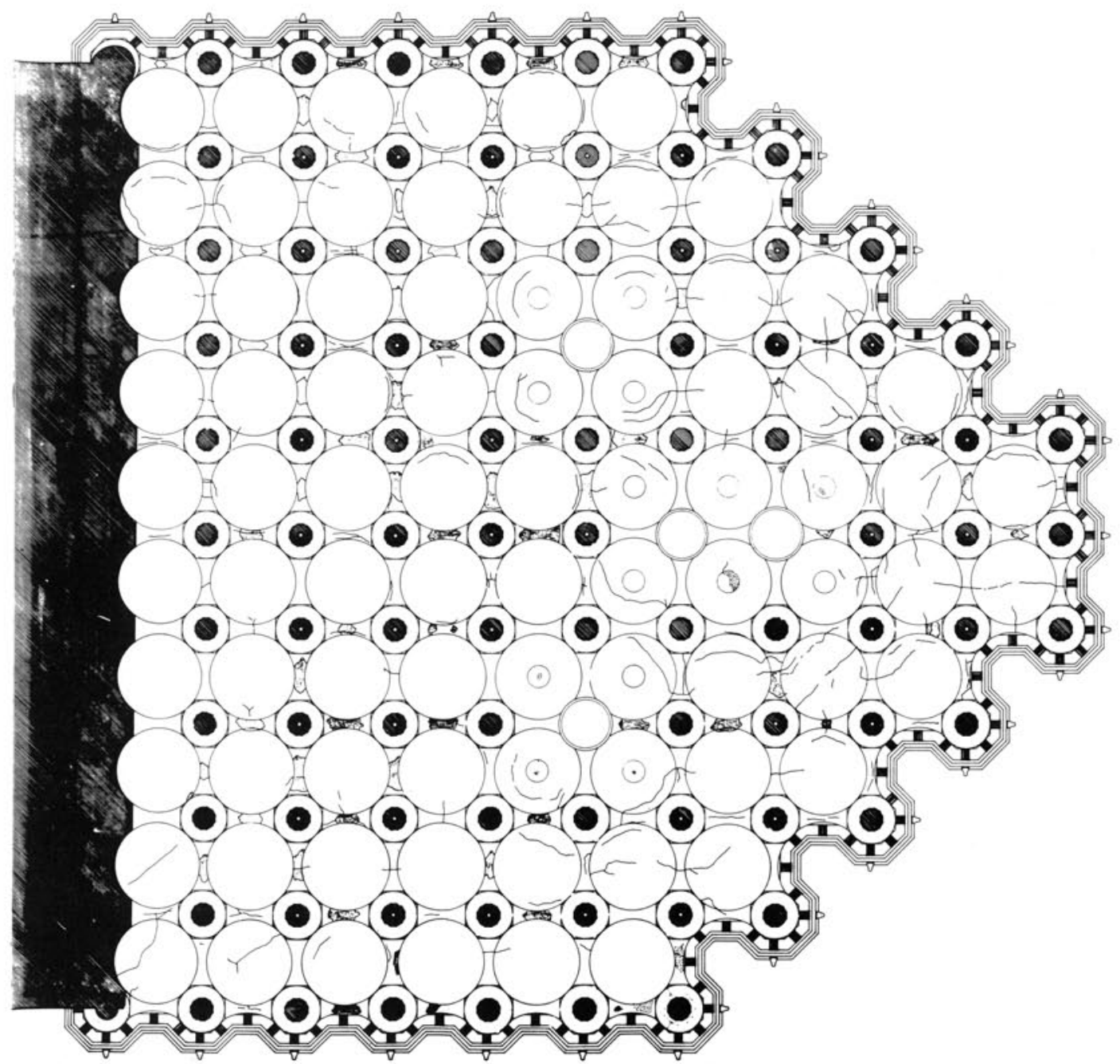

Fig. 5.-Planta de los casquetes de cobertura de la Sala Hipósita con indicación de las fisuras.

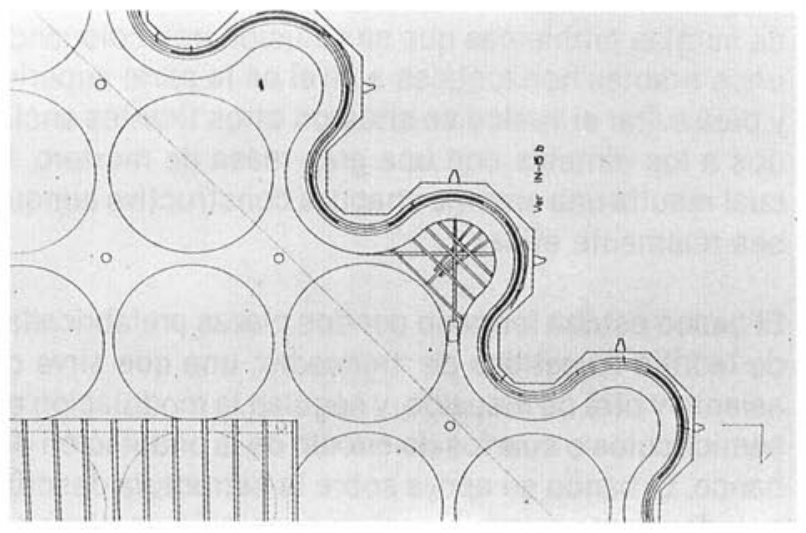

Fig. 6.-Detalle de la estructura de soporte del banco en las zonas laterales, donde el cuerpo tiene más vuelo. (Planimetria Fructuós Mañá, arquitecto).

(c) Consejo Superior de Investigaciones Científicas Licencia Creative Commons 3.0 España (by-nc)

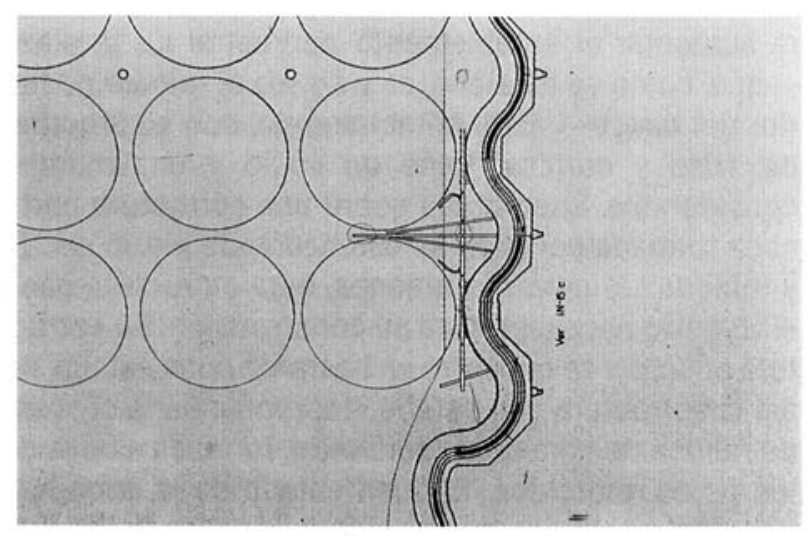

Fig. 7.-Detalle de la ingeniosa estructura de soporte del banco. (Planimetria Fructuós Mañá, arquitecto).

http://informesdelaconstruccion.revistas.csic.es 
El arquitrabe también estaba formado con obra de fábrica cerámica y reforzado con flejes, todo ello revocado exteriormente con mortero de cal imitando piedra; las lágrimas de los triglifos estaban sujetas con alambres que al humedecerse se oxidaban y se desprendian.

La forma de todo el conjunto, al ser un porche expuesto a la intemperie por su parte superior e inferior, está totalmente expuesta a todo tipo de cambios térmicos. La inclinación de los pilares perimetrales evitó en gran manera los efectos negativos de la intemperie, aunque el empuje de este pilar, que no está ligado al muro de la cisterna y que trabaja como un contrafuerte a tracción, producía fisuras que se tradujeron en la rotura de la bóveda de la cisterna; esto, añadido a que la cisterna se fundamenta sobre la tierra de relleno, ha producido todo un rosario de grietas en las bóvedas de los tramos perimetrales.

En cuanto a la restauración de los dinteles, éstos se han realizado totalmente de nuevo a base de piezas prefabricadas de hormigón sin retracción, a partir de un molde de poliéster armado y con armaduras de acero especial bañadas en resinas epoxi para aumentar la adherencia; las armaduras se han anclado a los capiteles a base de hormigonado con morteros especiales también sin retracción para asegurar la ausencia de esfuerzos que pudieran debilitar la fábrica existente. Las cúpulas se han zunchado entre sí a nivel del arranque para asegurar su rigidez pero aislando su perimetro del dintel mediante una junta de dilatación que garantiza la independencia de los elementos.

Las bóvedas y dinteles se han revestido exteriormente con trozos de azulejos, que a pesar de que a primera vista parecen uniformemente blancos, tienen infinidad de matices de tonalidades. En reparaciones anteriores no se habia respetado este hecho y la calidad plástica que daban las diferentes tonalidades había quedado fuertemente resentida.

Las columnas han sido reparadas a base del inyectado de lechada de cemento en las bases para conseguir su estabilización y recalce.

En cuanto a la impermeabilización de la cubierta el proyecto de restauración ha previsto una solución doble. En primer lugar, una capa de polibreal, aplicada directamente sobre el extradós de las cúpulas y dinteles de la cubierta, que actúa como barrera impermeable a las posibles condensaciones que pudiera originar la masa de relleno ligero (arlita expandida), situada sobre la fábrica de la cubierta; sobre este material de relleno una tela de PVC cubre e impermeabiliza todo el conjunto.

(c) Consejo Superior de Investigaciones Científicas

Licencia Creative Commons 3.0 España (by-nc)

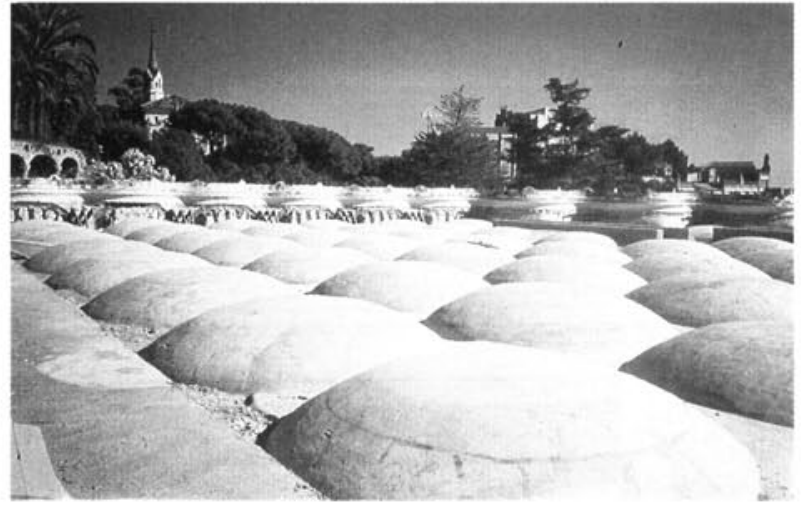

Fig. 8.-Vista de la plaza superior con los extradoses.

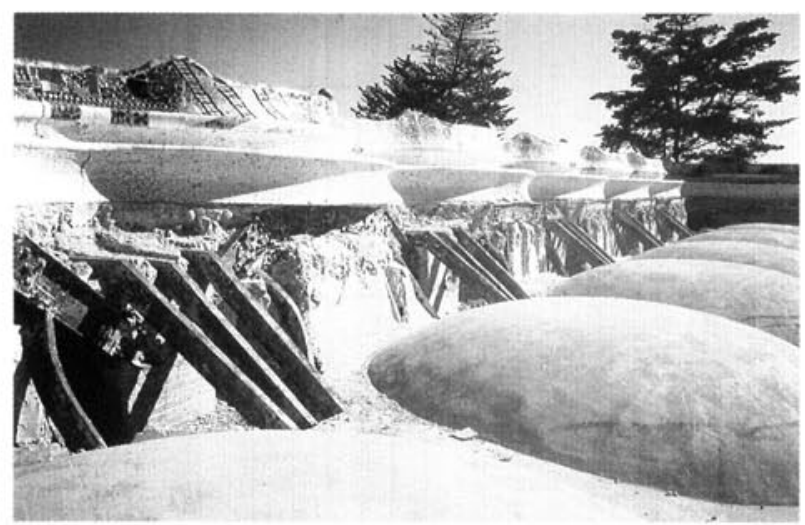

Fig. 9.-Estructura de sujeción del banco perimetral. (Foto Fructuós Mañá).

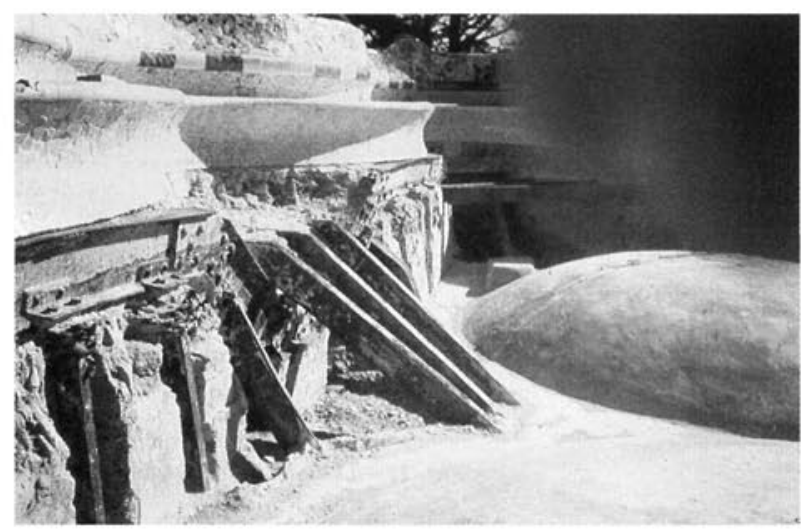

Fig. 10.-Jácenas de soporte del cuerpo volado del b̆anco perime. tral con su anclaje sobre los dinteles situados entre las cúpulas y el pórtico inclinado para la absorción de los empujes horizontales (Foto Fructuós Mañá). 


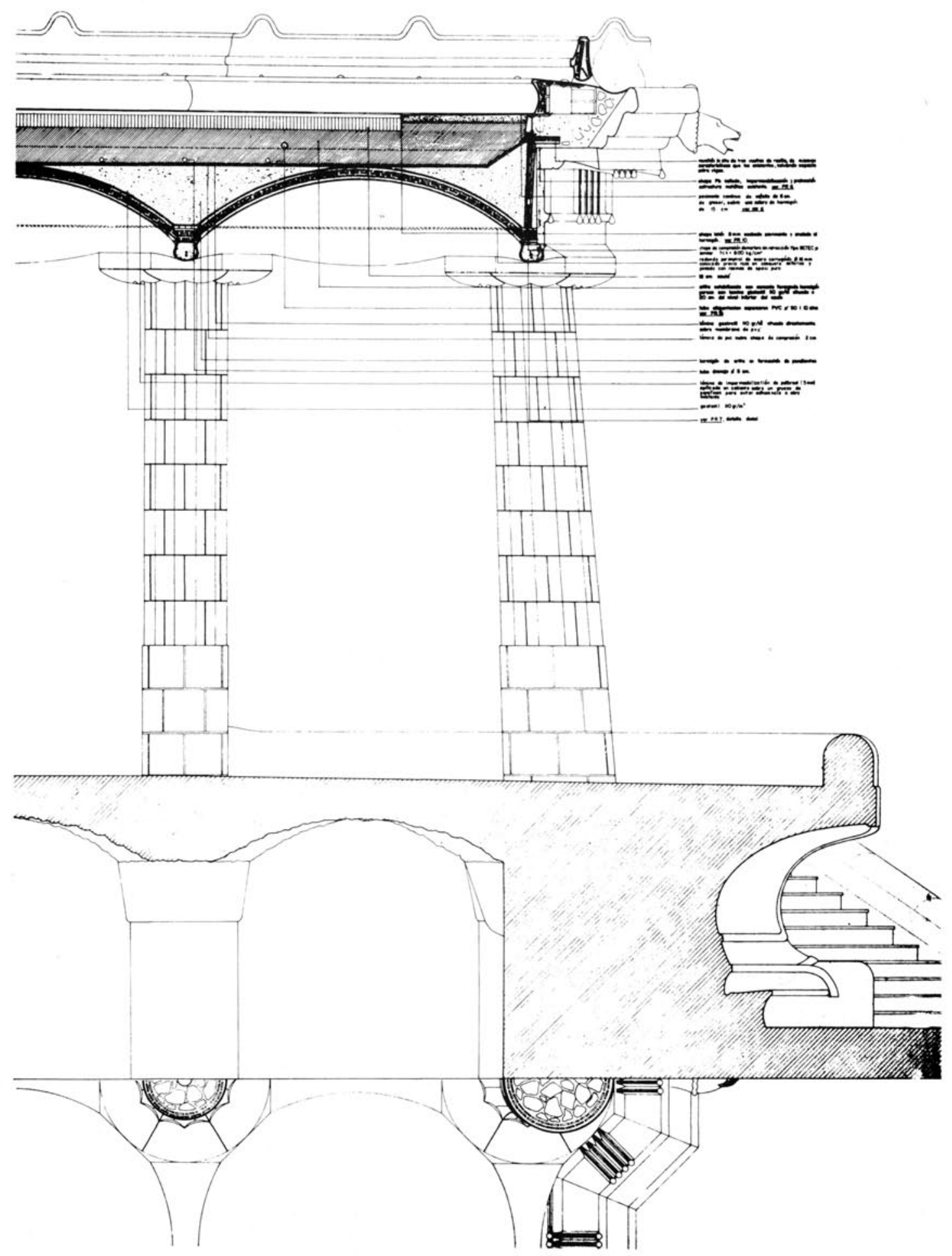

Fig. 11.-Detalle constructivo del pórtico y la cisterna. (Proyecto de restauración). 
El sistema original de desagüe de la plaza ha sido restituido con la introducción de nuevos materiales para mejorar su rendimiento. El sistema de drenaje es ahora a base de tubos de PVC perforados que garantizan la recogida y conducción de las aguas pluviales que se filtran por el sablón que recubre la plaza, hasta los bajantes situados en los huecos centrales de las columnas de la Sala Hipóstila. En la restauración se han trepanado de nuevo los pilares para introducir los tubos de PVC. Una reja a modo de aliviadero, construida en la cota más baja de la plaza, ayuda a desaguar su superficie.

Todo este recorrido del agua acaba en una cisterna, enterrada bajo la Sala Hipóstila, cuyo desagüe se produce a través del bello dragón de la escalinata de acceso a la plaza. La estructura de la cisterna ha sido recalzada ya que aparecia agrietada debido, en parte, a los asentamientos diferenciales, pero también como consecuencia de los movimientos del terreno de fundación y de los empujes inclinados que transmiten las colum. nas perimetrales de la sala sobre el muro perimetral de la cisterna, que es de sección recta.

De la plaza queda ahora por restaurar aún el famoso banco ondulado, un larguísimo elemento construido sin juntas de dilatación cuyo movimiento ha producido fisuras de 2, 3 y hasta $4 \mathrm{~mm}$. Está previsto hacer el sellado de las juntas con materiales elásticos y el restañado de fisuras, soluciones que si no son definitivas sí que pueden tener un buen período de validez. Dicen los arquitectos responsables de la restauración que "hay que tratar esta obra como un gran vegetal que necesita los cuidados del paciente jardinero que cada temporada le dará aquel cuidado propio de la estación".

Todo el conjunto se hizo con una idea de prefabricación más en el sentido de facilitar y organizarse el trabajo, que en el de buscar en ello un rendimiento económico.

La restauración del Park Güell ha reafirmado la idea de que cuando Gaudi se apartó de los materiales tradicionales que tan bien conocia, y se aventuró a utilizar materiales y sistemas poco experimentados, consiguió soluciones más ingeniosas que efectivas, unas soluciones que muchas veces han sido la más importante causa de degradación de su obra, ya que el descono. cimiento en profundidad del comportamiento de aquellos materiales hizo que se usaran mal o con espectativas demasiado optimistas.

En general toda la obra acusa un mal comportamiento del hierro utilizado como refuerzo de la obra cerámica, como tema constructivo típico del Modernismo y en especial de la obra de Gaudi, y que está dando muchos problemas para la conservación de este patrimonio, a causa de la gran cantidad de sales de la obra y que ayu-

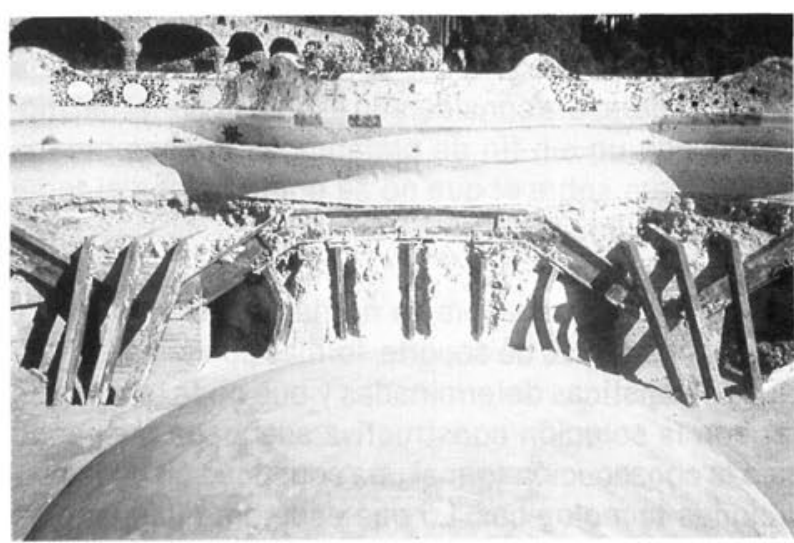

Fig. 12.-Detalle frontal del pórtico inclinado entre los conjuntos de jácenas en voladizo para el sporte del banco. (Foto Fructuós Mañá).

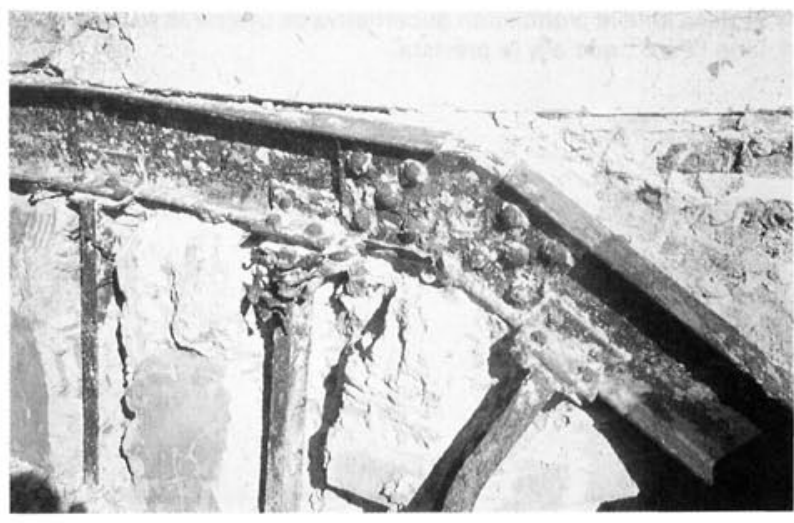

Fig. 13.-Detalle de los perfiles laminados de soporte del arquitrabe de coronación de la Sala Hipóstila. (Foto Fructuós Mañá).

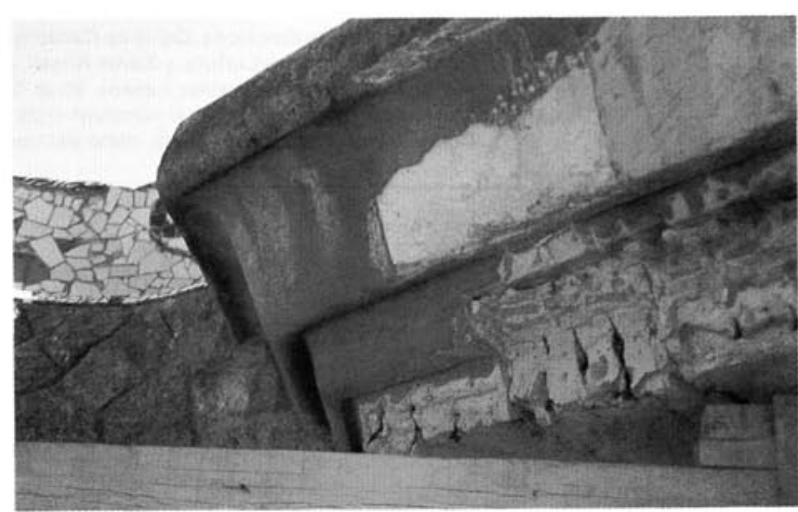

Fig. 14.-Arquitrabe de coronación con el acabado seperficial imitando piedra y la estructura interior formada por obra de fábrica de ladrillo, argamasa de cal y reforzada con los flejes retorcidos de hierro forjado (junio de 1990). 
86

Informes de la Construcción, Vol. 42 n. ${ }^{\circ} 408$, julio/agosto, 1990

dan y aceleran el proceso de oxidación. Hoy en día este problema se puede ver de antemano, pero en aquella época el hierro era considerado el gran material del momento, con un sin fin de pretendidas buenas prestaciones, pero sobre el que no se contemplaba el tema de la durabilidad.

En realidad en esta obra ya no hay correlación entre formas y sistemas de soporte, formas con unas exigencias paisajísticas determinadas y que nada tenían que ver con la solución constructiva adecuada buscando para la consecución formal una sofisticación de las soluciones tecnológicas. Lo que asombra realmente es que a partir de una tecnologia tan primaria fueran capaces de conseguir formas de la creatividad y belleza del Park Güell.

(1) En la mayor parte de la extensa bibliografia sobre Gaudi se ha utilizado la palabra "Park". Ello se hace por respeto a Gaudi, que - como ferviente catalanista - sugirió la utilización de la palabra inglesa ante la prohibición gubernativa de utilizar la palabra catalana "Parc", que era la prevista.

\section{Park Güell}

\section{Calle Olot s/n. Barcelona.}

Autor: Antoni Gaudí Cornet, arquitecto (1852-1926)

Fecha de construcción: 1900-1914

Propiedad actual: Ayuntamiento de Barcelona

Uso actual: jardín público (incluye un centro escolar y el Museo Gaudi)

Restauración: iniciada en 1986, en curso

Promotor: Ayuntamiento de Barcelona

Financiación: Ministerio de Cultura

Técnicos: José Antonio Martínez Lapeña y Elias Torres Tur, arquitectos directores. Fructuós Mañá, arquitecto consultor.

El Park Güell es una de las tres obras de Gaudi consideradas Patrimonio de la Humanidad por la UNESCO desde 1985. Es monumento nacional desde 1969.
GAUDI, CONSTRUCTOR

Número monogrático concebido y dirigido desde el Servicio del Patrimonio Arquifectónico de la Diputación de Barcelona (Calie Comte d'Urgell, 187, 08036 Barcelona)

Coordinación y dirección: Antoni González Moreno. Navarro arquitecto.

Lista de colaboradores: Redacción de textos: Juan Bassegoda, Cartes Buxadé, Pablo Carbó, Albert Casals, Antoni González, José Luís González, Joan Margarit, Josep Maria Moreno, Josep Rovira, Rafael Vila. Documentación: Raquel Lacuesta, Maria Gràcia Salvà, Dolors Forés, Maria Antónia Carras. $\mathrm{co}$, Imma Vilamala, historiadoras. Coordinación ilustraciones: Antonio Elizondo, arquitecto Dibujo: Txetxu Sanz, Maite Gómez, Salvador Santolaria, Jordi Serra, Joan Surís. Fotografia inédita: Joan Francés, Jordi Isern, Jaume Soler. Fotografía de la portada: Jordi Isern. Secretaria y proceso de textos: Carme Gas. Traducción de resumenes al inglés: James Townsend.

Agradecimientos: Amics de Gaudi, Archivo Nebreda, Arxiu GMN, Arxiu Mas, Arxiu Sagrada Familia, Ayuntamiento de Barcelona, Caixa de Catalunya, Cátedra Gaudi, Institut Municipal d'História de Barcelona, Ministerio de Cultura, y Xavier Aristó, Joan Farreras, Josep-Emili Hernández Cros, Fructuós Mañá, José Antonio Martinez Lapeña, Elias Torres.

La confección de este original conciuyó el 28 de junio de 1990, dia en que falleció el señor Eusebi Güell i Jover, vizconde de Güell, nieto del conde de Güeli, mecenas de Gaudi. (EPD). 